\title{
Cerebrospinal fluid drainage as a useful treatment option to relieve paraplegia after stent-graft implantation for acute aortic dissection type $B$
}

\author{
Tatjana Fleck, MD, ${ }^{\mathrm{a}}$ Doris Hutschala, MD, ${ }^{\mathrm{a}}$ Michael Weissl, MD, ${ }^{\mathrm{b}}$ Ernst Wolner, MD, ${ }^{\mathrm{a}}$ and

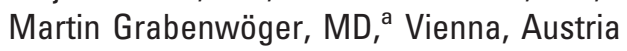

$\mathrm{E}$ ndovascular stent-graft placement has become a novel approach for the treatment of acute aortic dissection type B. The purpose of stent-graft placement is to seal the intimal tear to decompress the false lumen and decrease the risk of rupture. Complications such as paraplegia are reported to occur in about $7 \%$ of patients, which is in the range of open operative repair. ${ }^{1}$ There is ample evidence that the critical area of spinal cord perfusion lies between the intercostal arteries Th9 and Th12. Preservation of these arteries is associated with reduced risk of postoperative neurologic injury. ${ }^{2}$

\section{Clinical Summary}

A 53-year-old man was admitted to our emergency department after the onset of retrosternal pain 4 hours earlier. Multislice

\footnotetext{
From the Departments of Cardiothoracic Surgery a and Internal Medicine III, ${ }^{\text {b }}$ University of Vienna, Vienna, Austria.

Received for publication Aug 27, 2001; accepted for publication Oct 30, 2001.

Address for reprints: Tatjana Fleck, MD, Department of Cardiothoracic Surgery, University of Vienna, Leitstelle 20A, Währinger Gürtel 18-20, 1090 Vienna, Austria (E-mail: t9204604@ hotmail.com).

J Thorac Cardiovasc Surg 2002;123:1003-5

Copyright $\odot 2002$ by The American Association for Thoracic Surgery

$0022-5223 / 2002 \$ 35.00+0 \quad \mathbf{1 2 / 5 4 / 1 2 1 5 0 0}$

doi: $10.1067 / \mathrm{mtc} .2002 .121500$
}

computed tomographic scans showed an acute aortic dissection type B with impending rupture. The descending aorta was dissected from the left subclavian artery to the iliac arteries (Figure 1A). The primary entry site could be detected in the midportion of the descending thoracic aorta, resulting in a retrograde dissection to the left subclavian artery and an antegrade dissection down to the iliac arteries. A reentry site was found in the height of the renal arteries. Except for the inferior mesenteric artery, the visceral arteries were perfused from the true lumen. After informed consent was obtained, the right femoral artery was exposed with the patient under general anesthesia. A pigtail catheter (pigtail aortic flush super torque 6F; $65 \mathrm{~cm}$, Cordis, Inc, the Netherlands) was introduced into the proximal descending aorta, and thereafter a Gore stent graft (W. L. Gore \& Associates, Inc, Flagstaff, Ariz; diameter $37 \mathrm{~mm}$, length $150 \mathrm{~mm}$ ) was advanced into the sheath and deployed. To close the intimal tear, it was necessary to obliterate 3 distal pairs of intercostal thoracic arteries (Figure 2B). Nine hours after stenting, bilateral incomplete paraplegia developed with motor and sensory deficits affecting the right leg completely and the left leg partially. Cerebrospinal fluid (CSF) drainage was subsequently initiated by inserting a lumbar catheter at L3-L4. ${ }^{3}$

Initial liquor pressure was $45 \mathrm{~mm} \mathrm{Hg}$. To reach the target pressure of $15 \mathrm{~mm} \mathrm{Hg}$, we drained $160 \mathrm{~mL}$ of fluid. Pressure was monitored continuously over the next 96 hours, and CSF was drained freely by gravity whenever the pressure exceeded $15 \mathrm{~mm}$ $\mathrm{Hg}$. The patient regained leg movement after 12 hours and 


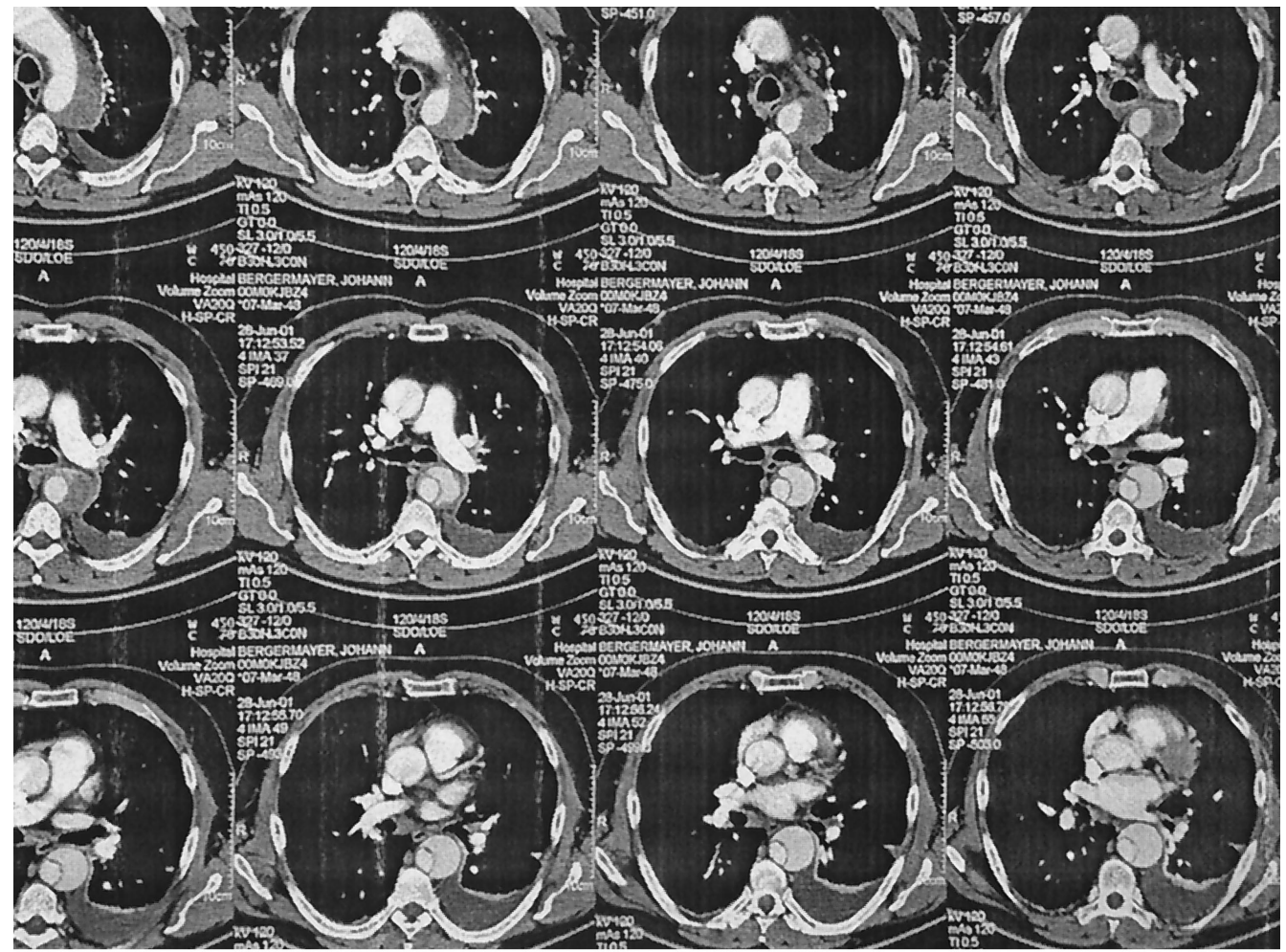

A

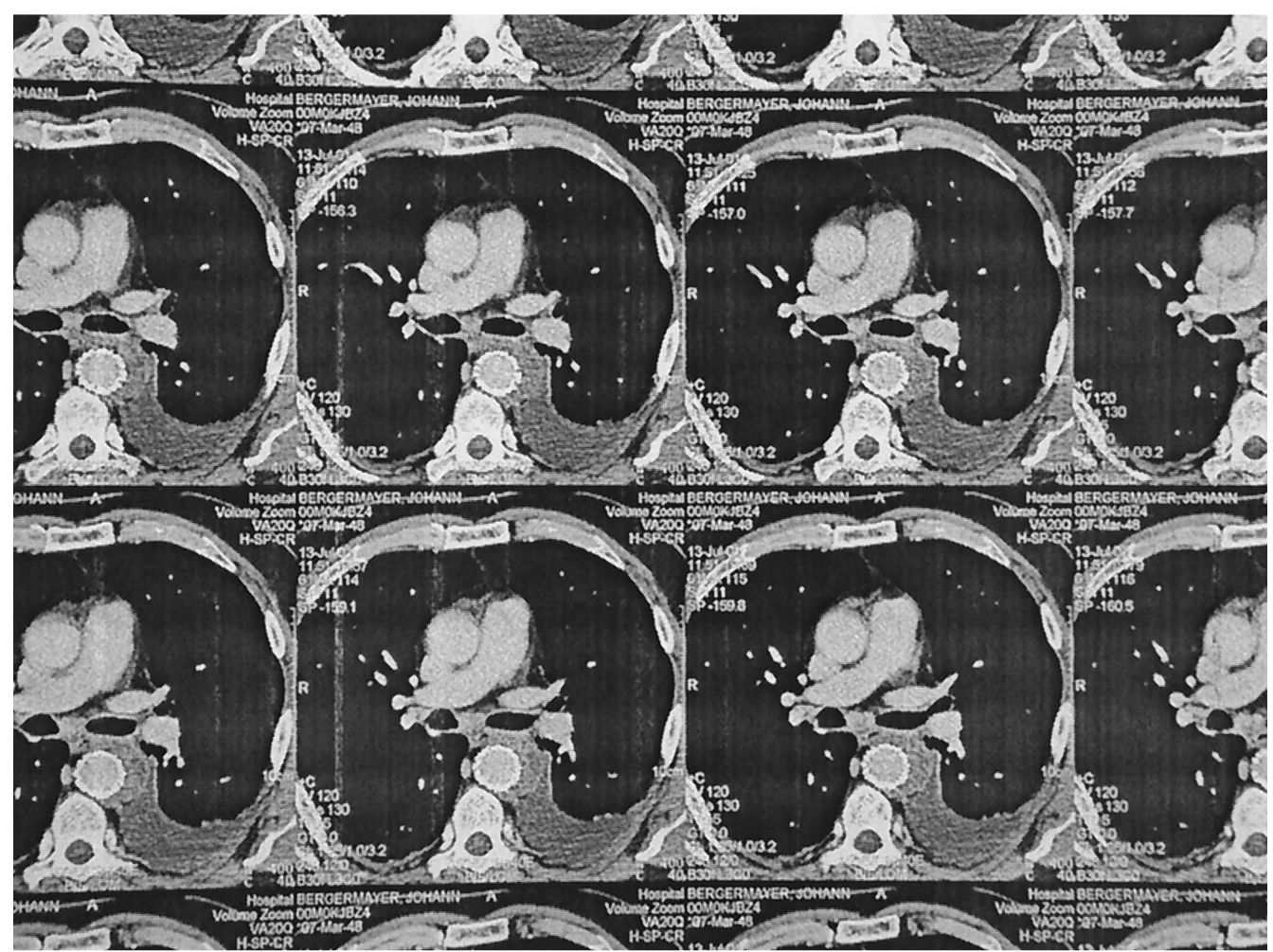

B

Figure 1A. Preoperative computed tomographic scan showing the perfused false lumen and the compressed true lumen. The entry site in the middle of the aortic arch is also seen by contrast enhancement. Figure 1B. Postoperative computed tomographic scan showing the obliterated false lumen and perfused true lumen. 


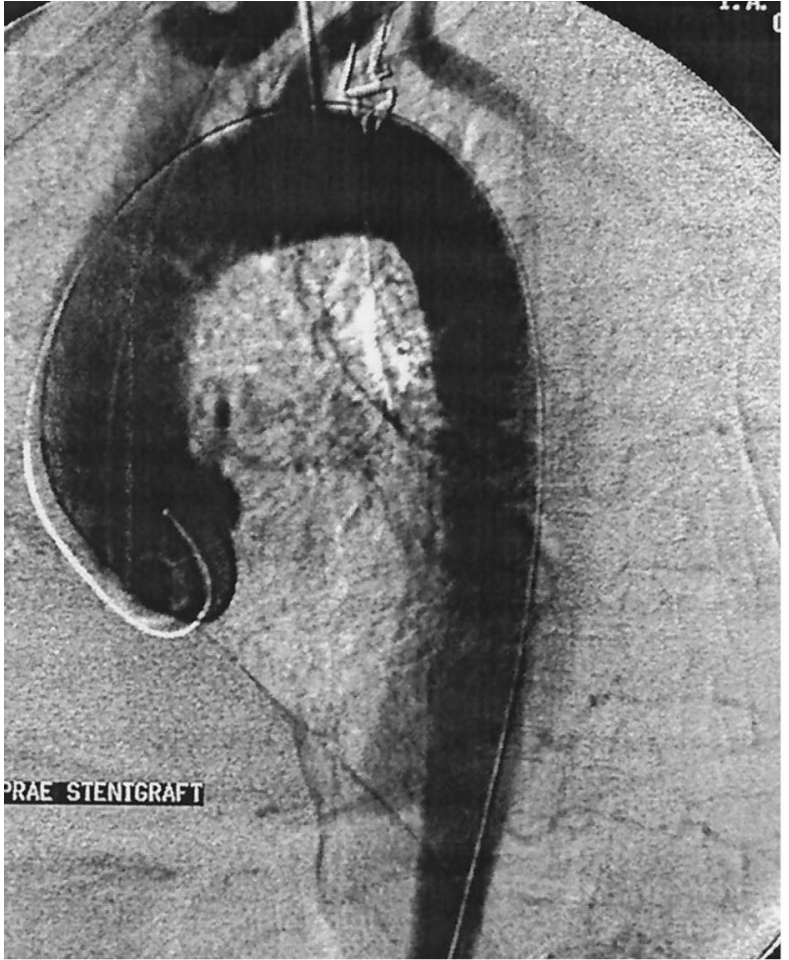

A

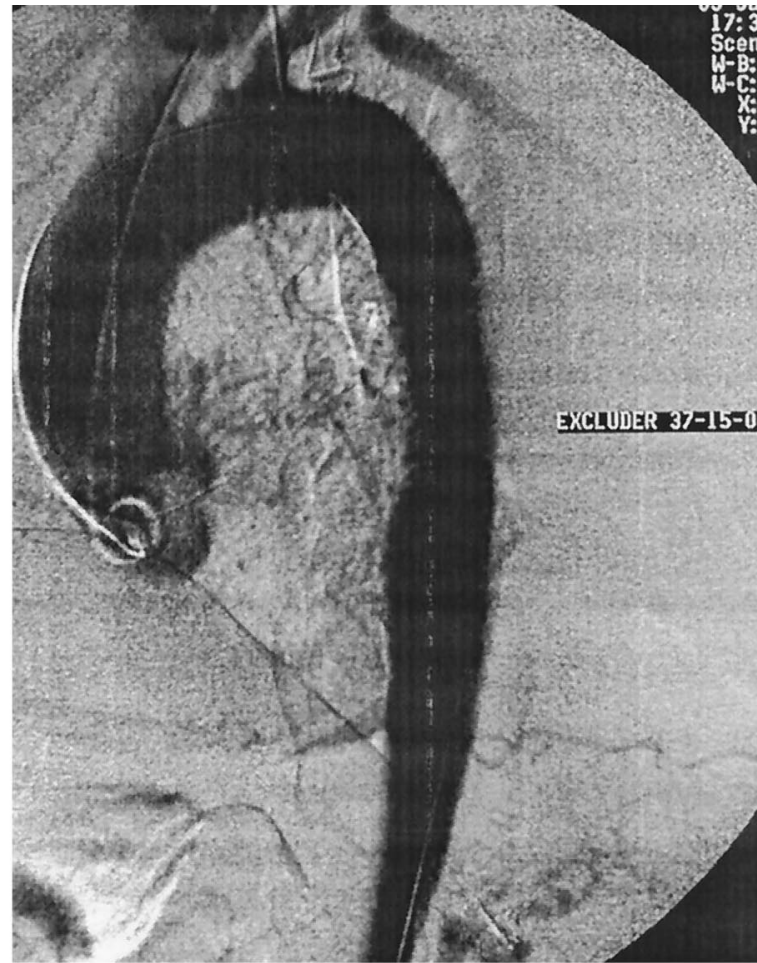

B

Figure 2. A, Angiogram before stenting showing 4 pairs of intercostal arteries. B, Angiogram after stent-graft placement showing occlusion of 3 pairs of intercostal arteries as a result of the stent graft.

achieved normal leg function after removal of the spinal catheter (96 hours). Total drainage volume was $800 \mathrm{~mL}$.

A follow-up computed tomographic scan performed 1 week after stenting showed a fully expanded and perfused stent graft, with no endoleak (Figure 1B). In the thoracic part of the aorta no perfusion of the false lumen was seen (Figure 2B).

The patient had an uneventful postoperative course and was discharged after 21 days with no remaining neurologic deficit.

\section{Discussion}

The phenomenon of delayed neurologic deficit after repair of thoracoabdominal aortic aneurysm was first described by Crawford and associates. ${ }^{4}$ Since then, several studies have shown the benefit of CSF drainage in reducing the incidence of postoperative neurologic deficit in thoracoabdominal aortic surgery. ${ }^{2,3,5} \mathrm{Re}$ cently, because of the rising number of stent-graft implantations as an alternative treatment option in a selected group of patients, attention has been paid to the possibility of neurologic deficit occurring after stent-graft placement. Cases of immediate and delayed paraplegia have also been reported. The accepted mechanism of spinal cord protection achieved by CSF drainage is decompression of the spinal compartment and restoration of spinal cord perfusion.

We report the benefit of CSF drainage to relieve paraplegia in a patient after stent-graft repair for acute aortic dissection type B. In our opinion, paraplegia was a result of increased liquor pressure in the spinal cord. It can be suggested that the increased liquor pressure was a consequence of reperfusion edema resulting from obliteration of 3 pairs of intercostal arteries by the stent graft. Therefore, CSF drainage was able to restore the microcirculatory flow in the spinal cord.

CSF drainage can be considered a useful treatment option in patients having neurologic deficits as a result of stent-graft placement in the distal thoracic aorta. Further investigations have to be made to evaluate the impact of CSF drainage in these patients to prevent or reduce the risk of postoperative neurologic deficit. Furthermore, prophylactic use of CSF drainage should be discussed, especially when the distal part of the thoracic aorta is affected.

\section{References}

1. Dake M, Kato N, Mitchell S, Semba C, Razavi M, Shimono T, et al. Endovascular stent-graft placement for the treatment of acute aortic dissection. $N$ Engl J Med. 1999;340:1546-52.

2. Huynh D, Miller C 3rd, Safi H. Delayed onset of neurologic deficit: significance and management. Semin Vasc Surg. 2000;13:340-4.

3. Tefera G, Acher C, Wynn M. Clamp and sew techniques in thoracoabdominal aortic surgery using naloxone and CSF drainage. Semin Vasc Surg 2000;13:325-30.

4. Crawford ES, Mizrahi EM, Hess KR, Coselli JS, Safi HJ, Patel VM The impact of distal aortic perfusion and somatosensory evoked potential monitoring on prevention of paraplegia after aortic aneurysm operation. J Thorac Cardiovasc Surg. 1988;95:357-67.

5. Coselli J, LeMaire S, Schmittling Z, Köksoy C. Cerebrospinal fluid drainage in thoracoabdominal aortic surgery. Semin Vasc Surg. 2000; 13:308-14. 